\title{
Reducibility of Platinum Supported on Nanostructured Carbons
}

\author{
Arie J. Plomp · Tim Schubert · Ulrich Storr • \\ Krijn P. de Jong · Johannes H. Bitter
}

Published online: 21 January 2009

(c) The Author(s) 2009. This article is published with open access at Springerlink.com

\begin{abstract}
The nanostructure of graphite like carbon, i.e. carbon nanofibers (CNF), carbon nanotubes (CNT) and carbon nanoplatelets (CNP), displayed a significant influence on the reducibility of platinum deposited on these carbons. The onset temperature for reduction increased from $461 \mathrm{~K}$ for Pt/CNF to $466 \mathrm{~K}$ for Pt/CNP and $487 \mathrm{~K}$ for $\mathrm{Pt} / \mathrm{CNT}$. The retarded reduction for Pt/CNT was related to the higher amount of acidic oxygen surface groups on this support resulting in a strong stabilization of the cationic platinum species. A higher reduction temperature for that sample increased the amount of metallic platinum, however the platinum particle size was larger $(2-11 \mathrm{~nm})$ compared to that of $\mathrm{Pt} / \mathrm{CNF}$ and $\mathrm{Pt} / \mathrm{CNP}$ (both 1-3 nm). The orientation of the graphene sheets had a significant influence on the selectivity for cinnamaldehyde hydrogenation: $\mathrm{Pt} / \mathrm{CNP}$ resulted in a higher selectivity towards cinnamyl alcohol compared to Pt/CNF.
\end{abstract}

Keywords Platinum catalysts - Carbon nanofibers · Carbon nanotubes - Carbon nanoplatelets - Reduction . Cinnamaldehyde hydrogenation

\section{Introduction}

Reduction temperature and sintering behavior of the metal(oxide) phase in supported metal(oxide) catalysts

\footnotetext{
A. J. Plomp · K. P. de Jong · J. H. Bitter ( $\square)$ Inorganic Chemistry and Catalysis, Utrecht University, P.O. Box 80083, Utrecht 3508 TB, The Netherlands e-mail: J.H.Bitter@uu.nl

T. Schubert · U. Storr FutureCarbon GmbH, Gottlieb-Keim-Straße 60, Bayreuth 95448, Germany
}

depend largely on parameters such as the nature of the support used or the synthesis method [1-3]. For example, Roman-Martinez et al. [2] showed for platinum supported on activated carbons that partial oxidation of the support resulted in higher platinum reduction temperatures and substantial hydrogen spill-over compared to the non-oxidized carbon supports. Da Silva et al. [4] deposited mono metallic platinum, platinum-iron and platinum-tin combinations on $\mathrm{TiO}_{2}$ and carbon. The TPR profiles of the mono metallic platinum catalysts showed that platinum is reduced at lower temperature on $\mathrm{TiO}_{2}$ compared to carbon ( $443 \mathrm{~K}$ and $473 \mathrm{~K}$ respectively). The addition of a second metal affected the platinum reduction temperature: for platinum-iron an increase of $20-40 \mathrm{~K}$ was observed.

For catalysts based on nanostructured carbon it can be expected that their reduction behavior is related to the orientation of the graphene layers with respect to the central axis. Three major classes of tubular carbons are distinguished, i.e. carbon nanotubes (CNT, graphene layers aligned with central axis), carbon nanoplatelets (CNP, graphene layers perpendicular with central axis) and carbon nanofibers (CNF, graphene layers at an angle between 0 and 90 degrees with central axis) [5]. All these nanostructured carbons attracted interest as heterogeneous catalyst support $[5,6]$.

Different examples can be found in which it was shown that the graphene orientation has an influence on the catalytic activity of supported metal catalysts. Motoyama et al. [7] investigated CNF, CNT and CNP-supported ruthenium for the hydrogenation of various aromatic compounds. Ruthenium was well dispersed (particle size $\sim 2.5 \mathrm{~nm}$ ) on CNP and resulted in high and reproducible catalytic activity, while for CNF and especially for CNT supported ruthenium the coexistence of large particles (ranging from 10 to $150 \mathrm{~nm}$ ) and small ones $(<4.5 \mathrm{~nm})$ 
was observed resulting in low hydrogenation activities. $\mathrm{Vu}$ et al. [8] deposited platinum and ruthenium on CNT and $\mathrm{CNF}$ and tested these catalysts for the cinnamaldehyde hydrogenation. They observed that in general the average metal particle size was smaller for CNF than for CNT. Two different CNT batches with different inner tube diameters (batch 1: $<10 \mathrm{~nm}$ and batch 2: 60-100 nm) and different BET surface areas (batch 1: $400 \mathrm{~m}^{2} / \mathrm{g}$ and batch $2: 40 \mathrm{~m}^{2} / \mathrm{g}$ ) were studied by Ma et al. [9]. The authors deposited platinum on the supports, which resulted in two different metal particles sizes (batch 1: $<2 \mathrm{~nm}$ and batch 2: $>5 \mathrm{~nm}$ ). These catalysts were tested for the cinnamaldehyde hydrogenation and large differences with respect to catalytic selectivity were found (selectivity to cinnamyl alcohol for batch 1: $<25 \%$ and batch 2: $>60 \%$ ) [9].

The above described results show that especially for CNT supported catalysts a wide variety of particle sizes is observed, which is accompanied by large differences with respect to catalytic activities or selectivities. This might be associated with the reduction behavior related to the graphene sheet orientation. The goal of the current study is to deposit platinum on CNF, CNT and CNP to investigate the role of graphene layer orientation on reducibility and catalytic activity of platinum for cinnamaldehyde hydrogenation. The latter reaction is sensitive to subtle changes in the support surface composition of nanostructured carbons as shown earlier by our group [10, 11].

\section{Experimental}

The $\mathrm{Ni} / \mathrm{SiO}_{2}$ (20 wt $\%$ ) growth catalyst was prepared via homogeneous deposition precipitation using $17.0 \mathrm{~g}$ silica (Degussa; Aerosil 200), $21.1 \mathrm{~g}$ nickel nitrate hexahydrate (Acros; 99\%) and $13.9 \mathrm{~g}$ urea (Acros; p.a.) in $1 \mathrm{~L}$ demineralized water according to an earlier described procedure [12]. The growth and oxidation of CNF was performed as described earlier [13].

CNT (multi-walled class 1) and CNP (carbon nanofiberplatelets) were obtained from FutureCarbon $\mathrm{GmbH}$, Germany. Both materials $(9 \mathrm{~g})$ were refluxed for $1 \mathrm{~h}$ in an aqueous $\mathrm{KOH}$ solution $(1 \mathrm{M} ; 250 \mathrm{~mL})$ and, after filtering and washing, refluxed for $2 \mathrm{~h}$ in concentrated nitric acid $(250 \mathrm{~mL}$; Merck; $65 \%)$ and filtered again. The oxidized residue was washed three times with demineralized water and dried overnight at $393 \mathrm{~K}$.

Platinum was deposited on oxidized CNF, CNP and CNT using ion adsorption, as described for platinum tetraammine nitrate by $\mathrm{Hao}$ et al. [14]. Oxidized carbon material $(5.00 \mathrm{~g})$ was suspended in demineralized water $(250 \mathrm{~mL})$ and the $\mathrm{pH}$ was adjusted to 10 using ammonium hydroxide (Merck; conc.). $\mathrm{Pt}\left(\mathrm{NH}_{3}\right)_{4}\left(\mathrm{NO}_{3}\right)_{2} \quad$ (0.202 g; Aldrich) was added and the slurry was stirred for $2 \mathrm{~h}$. If necessary, the $\mathrm{pH}$ was again adjusted to 10 . Next, the slurry was filtered using a Millipore filter and shortly washed using aqueous ammonium hydroxide solution of $\mathrm{pH} 10$. After drying overnight at $393 \mathrm{~K}$, the obtained material was reduced in $\mathrm{H}_{2} / \mathrm{N}_{2}$-flow $(100 \mathrm{~mL} / \mathrm{min} ; 10 \% \mathrm{v} / \mathrm{v})$ at $473 \mathrm{~K}$ $(1 \mathrm{~h}$; ramp $5 \mathrm{~K} / \mathrm{min})$ and the resulting materials were denoted as $\mathrm{Pt} / \mathrm{CNF}, \mathrm{Pt} / \mathrm{CNP}$ and $\mathrm{Pt} / \mathrm{CNT}$. A batch of $\mathrm{Pt} / \mathrm{CNT}$ was also reduced in $\mathrm{H}_{2} / \mathrm{N}_{2}$-flow $(100 \mathrm{~mL} / \mathrm{min}$; $10 \% \mathrm{v} / \mathrm{v})$ at $503 \mathrm{~K}(1 \mathrm{~h}$; ramp $5 \mathrm{~K} / \mathrm{min})$. This catalyst is denoted as Pt/CNT-red503.

Platinum on nanostructured carbons catalysts $(1 \mathrm{~g}$; sieve fraction 25-90 $\mu \mathrm{m}$ ) were tested for the cinnamaldehyde hydrogenation as described earlier [13]. The conversion of cinnamaldehyde and selectivity to cinnamyl alcohol were calculated as described before [13].

The metal weight-loading of the samples was determined using ICP-OES. The measurements were performed using a SPECTRO CIROS ${ }^{\mathrm{CCD}}$ ICP-Spectrometer. Each sample was destructed by heating in aqua regia (1:3 mixture of $\mathrm{HNO}_{3}: \mathrm{HCl}$ ) before analysis.

TPR experiments were performed using a Micromeritics AutoChem II 2920. After drying at $393 \mathrm{~K}$, the non-reduced catalysts were analyzed using a flow of $\mathrm{H}_{2} / \mathrm{Ar}(5 \% \mathrm{v} / \mathrm{v}$; $50 \mathrm{~mL} \mathrm{STP} / \mathrm{min}$ ) and a temperature ramp of $5 \mathrm{~K} / \mathrm{min}$. Different amounts of sample were used $(0.17-0.33 \mathrm{~g})$. The reproducibility of the machine was experimentally determined to be $\pm 2 \mathrm{~K}$. Hydrogen consumptions were normalized to the sample weight. The onset reduction temperature was determined by extrapolation of the baseline and extrapolation of the tangent at the inflection point of the first peak slope. The point of intersection of these two lines is reported as the onset reduction temperature.

Acid-base titrations were performed using a Titralab TIM 880 apparatus. To $60 \mathrm{~mL}$ of $0.1 \mathrm{M} \mathrm{KCl} 0.05 \mathrm{~g}$ $\mathrm{Pt} / \mathrm{CNF}$ was added. A solution of $0.01 \mathrm{M} \mathrm{NaOH}$ and $0.1 \mathrm{M}$ $\mathrm{KCl}$ was used as titrant. The titrant consumption to reach a $\mathrm{pH}$ of respectively 5 and 7.5 were used to calculate the amount of strong (at pH 5) and total (at pH 7.5) acidic sites on the catalysts. The stronger acidic groups are expected to be the carboxylic acid surface groups [15].

TEM was performed using a Tecnai 20 FEG operating at $200 \mathrm{kV}$ and a point resolution of $2.7 \AA$. The microscope was equipped with an EDX detector.

Nitrogen physisorption was performed at $77 \mathrm{~K}$, using a Micromeritics Tristar 3000 V6.01 to determine BET surface areas and pore volumes (single point adsorption at $\left.\mathrm{P} / \mathrm{P}_{0}>0.994\right)$. Prior to the physisorption measurements, the samples were dried in flowing nitrogen at $473 \mathrm{~K}$ for about $14 \mathrm{~h}$.

Hydrogen chemisorption measurements were performed using a Micromeritics ASAP 2020. Samples were dried at $373 \mathrm{~K}$ in vacuum followed by cooling to room temperature. Next, the samples were re-reduced in flowing 
hydrogen at $473 \mathrm{~K}$ for $60 \mathrm{~min}$ (heating ramp $5 \mathrm{~K} / \mathrm{min}$ ). Afterwards, the samples were degassed for at least $30 \mathrm{~min}$ at a pressure of $<13.3 \mathrm{~Pa}$ at $473 \mathrm{~K}$ to remove chemisorbed hydrogen and water. The isotherms were measured at $313 \mathrm{~K}$ and the mass was determined afterwards. The presented $\mathrm{H} / \mathrm{Pt}$ ratios are based on the amounts adsorbed at zero pressure, which are calculated by extrapolation of the linear part of the isotherm. Estimated average particle sizes and dispersions are based on spherical geometry and an adsorption stoichiometry of $\mathrm{H} / \mathrm{Pt}_{\mathrm{s}}=1$. Based on these data and assuming full reduction, average particle sizes were calculated as described by Scholten et al. [16]:

$d=10^{21} \frac{6 \times M \times \rho_{\text {site }}}{D \times \rho_{\text {metal }} \times N}$

where $\mathrm{d}$ is particle size $(\mathrm{nm}), \mathrm{M}$ the atomic weight $(195.1 \mathrm{~g} / \mathrm{mol}), \rho_{\text {site }}$ the platinum surface site density $(12.5$ $\mathrm{Pt}$ atoms $\left./ \mathrm{nm}^{2}\right)$ [16], D is dispersion $(\mathrm{H} / \mathrm{Pt}), \rho_{\text {metal }}$ the metal density $\left(21.45 \mathrm{~g} / \mathrm{cm}^{3}\right)$ and $\mathrm{N}$ the Avogadro constant giving $\mathrm{d}=1.13 / \mathrm{D}(\mathrm{nm})$.

\section{Results and Discussion}

Some of the structural parameters of the oxidized carbons are compiled in Table 1 and high resolution TEM images are depicted in Fig. 1. The measured BET surface areas were $78 \mathrm{~m}^{2} / \mathrm{g}$ for CNP, $178 \mathrm{~m}^{2} / \mathrm{g}$ for CNF and $247 \mathrm{~m}^{2} / \mathrm{g}$ for CNT. The increase in BET surface area is ascribed to a decrease in fiber diameter (Table 1) for the different carbon materials (CNP: 40-200 nm, CNF: $25-40 \mathrm{~nm}$ and CNT: $10-25 \mathrm{~nm}$ ), which will result in a larger surface-to-volume ratio.

The pore volume established from nitrogen physisorption was significantly higher for CNT $(1.01 \mathrm{~mL} / \mathrm{g})$ than for
CNP $(0.24 \mathrm{~mL} / \mathrm{g})$ and CNF $(0.28 \mathrm{~mL} / \mathrm{g})$. No micropores were found in the used materials. The substantially larger pore volume observed for CNT compared to CNF and CNP is ascribed to the fact that CNT has a lower bulk density combined with a small particle size. Therefore, a large intratubular pore volume is created. Moreover, the individual fibers in CNP and CNF seem to be more entangled as compared to the thinner CNT. This may result in a higher pore volume for CNT [17].

ICP-OES showed that platinum loadings for the catalysts were 1.7-1.8 wt\% (Table 2). The amount of acidic, oxygen surface groups was determined using acid-base titrations. CNT displayed $0.50 \mathrm{mmol}$ strong acidic sites per gram CNT, while $0.10 \mathrm{mmol}$ strong acidic sites per gram were found for CNP and $0.17 \mathrm{mmol}$ strong acidic sites per gram for CNF. At pH $7.50 .84 \mathrm{mmol}$ acidic sites per gram CNT was titrated, while for CNF and CNP the results were similar: $0.23 \mathrm{mmol}$ acidic sites per gram material. For CNT the oxygen containing groups must be located on defects in the graphene sheets [18], which are either present in the as prepared materials or can be formed during the nitric acid treatment used to introduce the oxygen surface groups [19]. Also after platinum deposition, titrations were performed to determine the amount of acidic, oxygen surface groups. At $\mathrm{pH} 5$ this resulted in $0.02 \mathrm{mmol}$ acidic sites per gram for $\mathrm{Pt} / \mathrm{CNF}$ and $\mathrm{Pt} / \mathrm{CNP}$ and in $0.06 \mathrm{mmol}$ acidic sites per gram for $\mathrm{Pt} / \mathrm{CNT}$ and $\mathrm{Pt} / \mathrm{CNT}$-red503. For Pt/CNF and $\mathrm{Pt} / \mathrm{CNP}$ $0.07 \mathrm{mmol}$ acidic sites per gram were found while for $\mathrm{Pt} / \mathrm{CNT}$ and Pt/CNT-red503 0.14 and $0.13 \mathrm{mmol}$ acidic sites per gram were present respectively at $\mathrm{pH}$ 7.5.

The TPR profiles of the materials after synthesis and drying are depicted in Fig. 2. The peak between 450 and $575 \mathrm{~K}$ represents the platinum reduction, while the peak at higher temperature is ascribed to gasification of the supports. The onset temperature for reduction was determined
Table 1 Physical properties of the oxidized supports

\begin{tabular}{llll}
\hline & Oxidized CNF & Oxidized CNP & Oxidized CNT \\
\hline BET surface area $\left(\mathrm{m}^{2} / \mathrm{g}\right.$; after oxidation) & 178 & 78 & 247 \\
Pore volume based on $\mathrm{N}_{2}$-physisorption $(\mathrm{mL} / \mathrm{g})$ & 0.28 & 0.24 & 1.01 \\
mmol acidic sites/g material at $\mathrm{pH} 5$ & 0.17 & 0.10 & 0.50 \\
mmol acidic sites/g material at $\mathrm{pH} 7.5$ & 0.23 & 0.23 & 0.84 \\
Fiber diameter (nm; based on TEM) & $25-40$ & $40-200$ & $10-25$
\end{tabular}
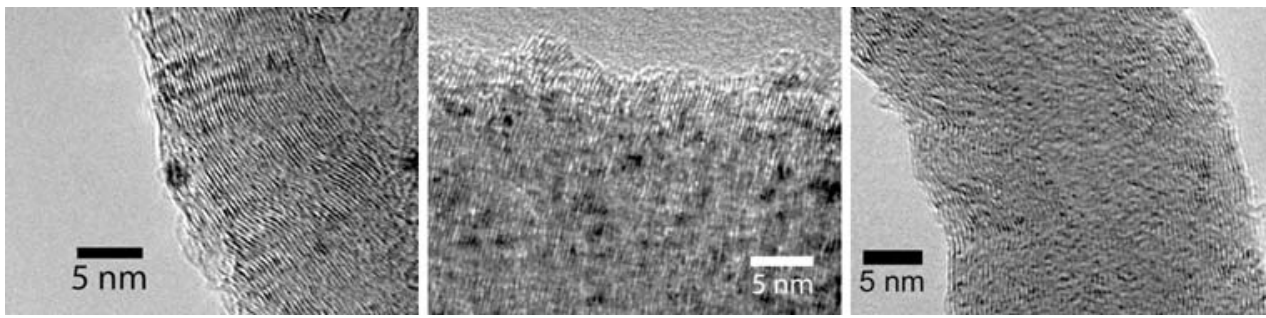

Fig. 1 High-resolution TEM image of oxidized CNF (left), CNP (middle) and CNT (right). For CNF, an image with some platinum particles is depicted 
Table 2 Physical properties of the catalysts n.d. not determined

a Based on $\mathrm{H}_{2}$-chemisorption data

\begin{tabular}{lllll}
\hline & Pt/CNF & Pt/CNP & Pt/CNT & Pt/CNT-red503 \\
\hline Metal loading (wt\%) & 1.8 & 1.8 & 1.7 & 1.7 \\
H/Pt ratio & 0.65 & 0.64 & 0.17 & 0.35 \\
Particle size (nm; based on $\mathrm{H}_{2}$-chemisorption) & 1.7 & 1.8 & 6.7 & 3.2 \\
Average particle size (nm; based on TEM) & 1.6 & 2.1 & n.d. & 4.2 \\
mmol acidic sites/g material at pH 5 & 0.02 & 0.02 & 0.06 & 0.06 \\
mmol acidic sites/g material at pH 7.5 & 0.07 & 0.07 & 0.14 & 0.13 \\
Initial TOF $\left(\mathrm{s}^{-1}\right)^{\mathrm{a}}$ & 0.05 & 0.07 & 0.05 & 0.07 \\
\hline
\end{tabular}
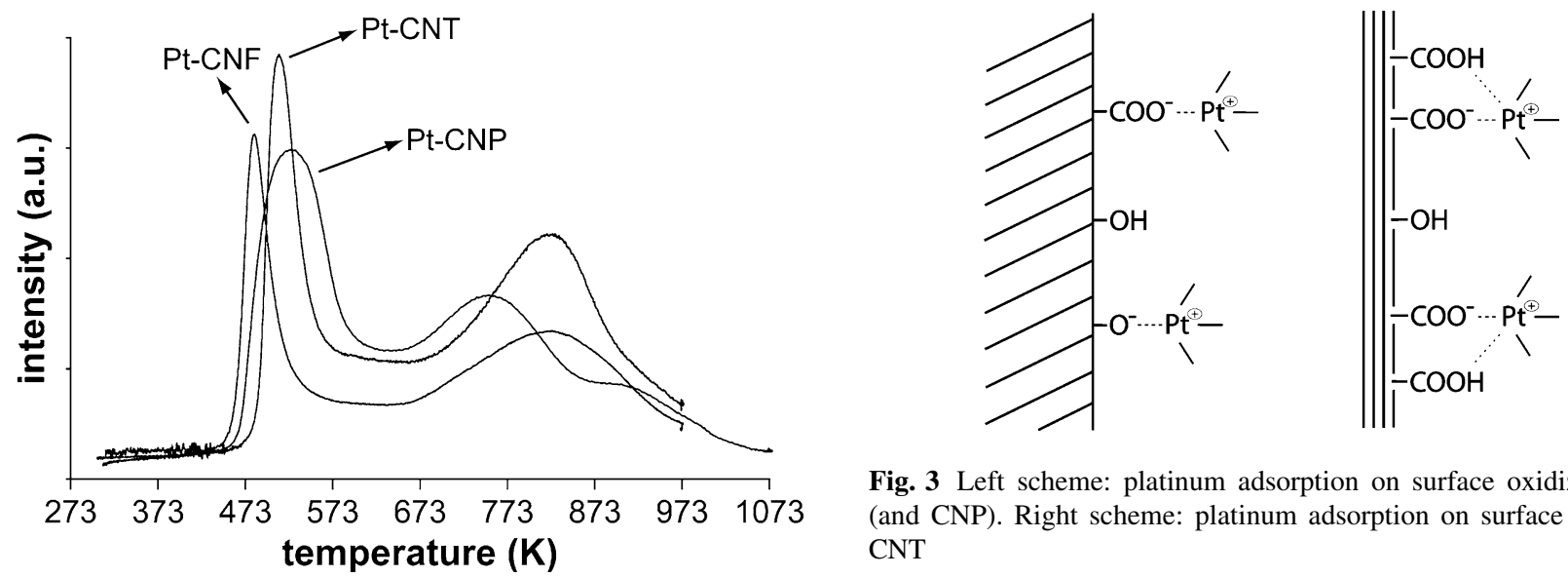

Fig. 3 Left scheme: platinum adsorption on surface oxidized CNF (and CNP). Right scheme: platinum adsorption on surface oxidized CNT

Fig. 2 TPR profiles of the non-reduced catalysts

to be $461 \mathrm{~K}$ for $\mathrm{Pt} / \mathrm{CNF}$, $466 \mathrm{~K}$ for $\mathrm{Pt} / \mathrm{CNP}$ and $487 \mathrm{~K}$ for $\mathrm{Pt} / \mathrm{CNT}$. Thus the reduction for $\mathrm{Pt} / \mathrm{CNT}$ is retarded compared to $\mathrm{Pt} / \mathrm{CNF}$ and $\mathrm{Pt} / \mathrm{CNP}$. The amount of platinum per gram material is approximately the same for all catalysts (i.e. $0.09 \mathrm{mmol} \mathrm{Pt} / \mathrm{g}$ material; see also Table 2). Titrations showed that CNT have the highest amount of acidic sites i.e. $0.50 \mathrm{mmol}$ acidic sites $/ \mathrm{g}$ at $\mathrm{pH} 5$ and $0.84 \mathrm{mmol} / \mathrm{g}$ at $\mathrm{pH} 7.5$ which is a 5-9 time excess compared to the amount of platinum deposited on this material. It has been shown earlier by Toebes et al. [20] that acidic oxygen surface groups are required to anchor platinum on CNF. Even after metal deposition still CNT have the highest amount of acidic sites. Since it is known that acidic oxygen surface groups are required to anchor platinum, it is speculated that the high amount of acidic oxygen surface groups on CNT resulted in a strong binding and stabilization of the cationic platinum. The formation of metallic platinum particles during reduction might therefore be hindered, which in turn results in a higher reduction temperature for this sample compared to $\mathrm{Pt} / \mathrm{CNF}$ and $\mathrm{Pt} / \mathrm{CNP}$ (see Fig. 3). It has been described in literature that the reduction temperature of palladium on nanostructured carbon is affected by and related to the presence of stable acidic surface groups [21]. This is in good agreement with our results.

It must be noted here that during metal deposition and reduction more oxygen surface groups are removed on
CNT (i.e. $0.84-0.14=0.7 \mathrm{mmol} / \mathrm{g}$ ) compared to $\mathrm{Pt} / \mathrm{CNF}$ and $\mathrm{Pt} / \mathrm{CNP}(0.23-0.07=0.16 \mathrm{mmol} / \mathrm{g})$. These groups can decompose and being removed due to e.g. hydrogen spillover during reduction [22]. The substantial removal of oxygen surface groups for CNT is ascribed to the fact that this material has the highest concentration of oxygen surface groups present after oxidation of this material. As a consequence, more oxygen surface groups are in the vicinity of platinum resulting in a relative high removal of these groups.

The first peak in the TPR profile for Pt/CNF is clearly the smallest and is related to platinum reduction. It is calculated that for this peak the theoretical $\mathrm{H}_{2} / \mathrm{Pt}$ ratio is around 6 , which is above the expected value of 1 . This is probably the result of the formation of other gases during the reduction/anion decomposition such as nitrogen oxides, ammonia, $\mathrm{CO}$ and $\mathrm{CO}_{2}$ (the latter two gases originate from support gasification [22, 23]), which will affect the TCD signal making quantitative statements obsolete.

$\mathrm{H} / \mathrm{Pt}$ ratios of the catalysts were calculated using hydrogen chemisorption and resulted for $\mathrm{Pt} / \mathrm{CNF}$ in 0.65 , $\mathrm{Pt} / \mathrm{CNP}$ in $0.64, \mathrm{Pt} / \mathrm{CNT}$ in 0.17 and $\mathrm{Pt} / \mathrm{CNT}$-red503 in 0.35 . Based on these data, average particle sizes were calculated and the results are given in Table 2. Platinum particle sizes were also analyzed using TEM (see Fig. 4). $\mathrm{Pt} / \mathrm{CNF}$ and $\mathrm{Pt} / \mathrm{CNP}$ showed platinum particles of $1-3 \mathrm{~nm}$, while for Pt/CNT, TEM did not show platinum particles. For the latter catalyst, the presence of platinum was 
Fig. 4 TEM images of the catalysts a: Pt/CNP Pt particles of $1-3 \mathrm{~nm} \mathbf{b}: \mathrm{Pt} / \mathrm{CNF} \mathrm{Pt}$ particles of $1-3 \mathrm{~nm}$ c: $\mathrm{Pt} / \mathrm{CNT}$ no Pt particles detected (the latter catalysts were reduced at $473 \mathrm{~K}) \mathbf{d}$ : Pt/CNT-red503 (reduction at $503 \mathrm{~K}$ ) Pt particles of $2-11 \mathrm{~nm}$ were observed
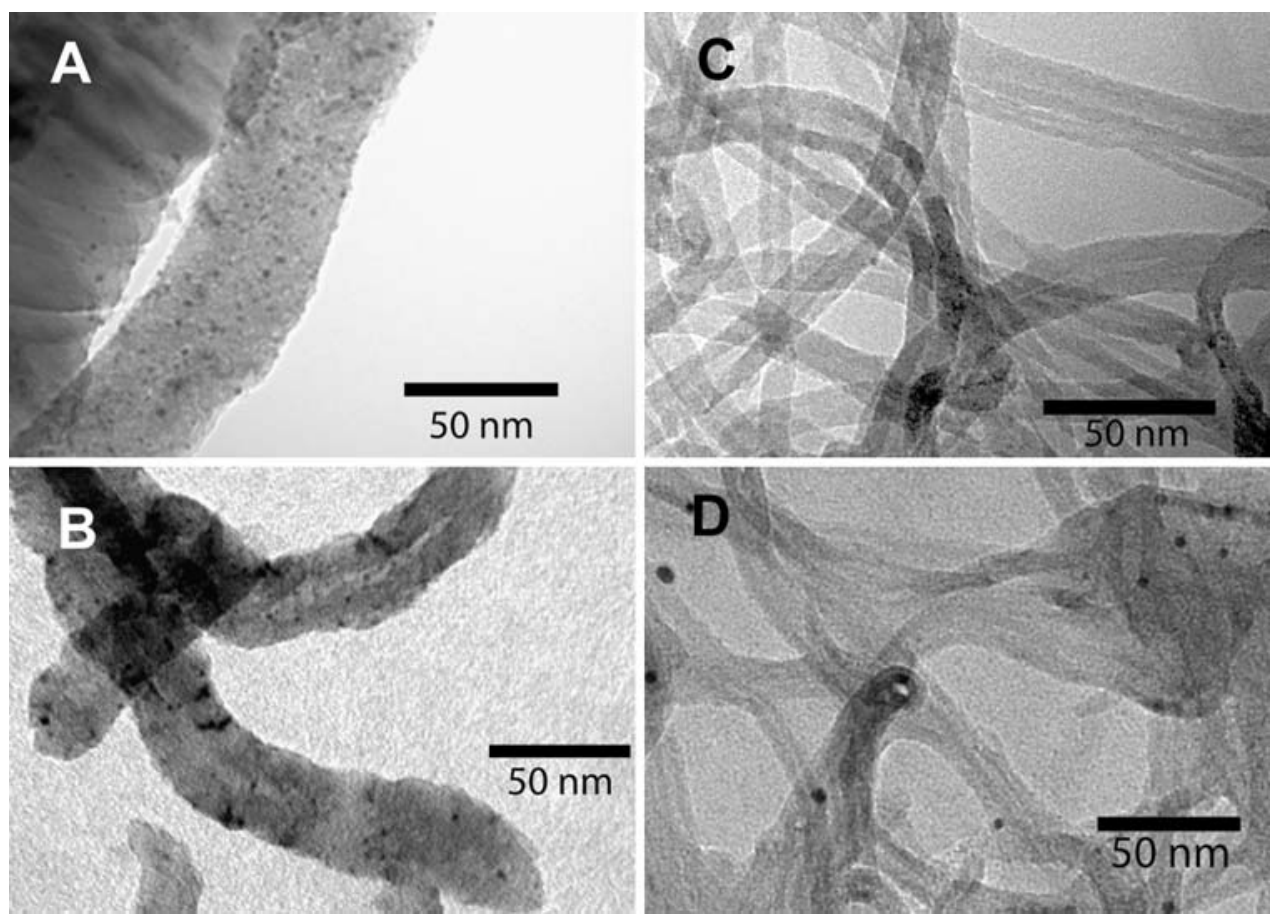

confirmed using TEM-EDX and ICP-OES. For Pt/CNTred503 large platinum particles, ranging from 2 to $11 \mathrm{~nm}$ were observed. Histograms of the observed particle size distribution of the different catalysts are compiled in Fig. 5. Based on TEM histograms the average particle sizes were calculated for all catalysts (see Table 2). As mentioned before, TEM did not show unambiguously the presence of platinum particles for $\mathrm{Pt} / \mathrm{CNT}$, though ICP-OES and TEM-EDX confirmed the presence of platinum. Also hydrogen chemisorption resulted in a low $\mathrm{H} / \mathrm{Pt}$ ratio, which shows that at least some platinum is present in the metallic state. These results are inconsistent with the observations using TEM, unless the sample is not wellreduced. The TPR profile of Pt/CNT suggests that this might be the case and therefore a reduction of $\mathrm{Pt} / \mathrm{CNT}$ at $503 \mathrm{~K}$ was performed. The measured $\mathrm{H} / \mathrm{Pt}$ ratio of this

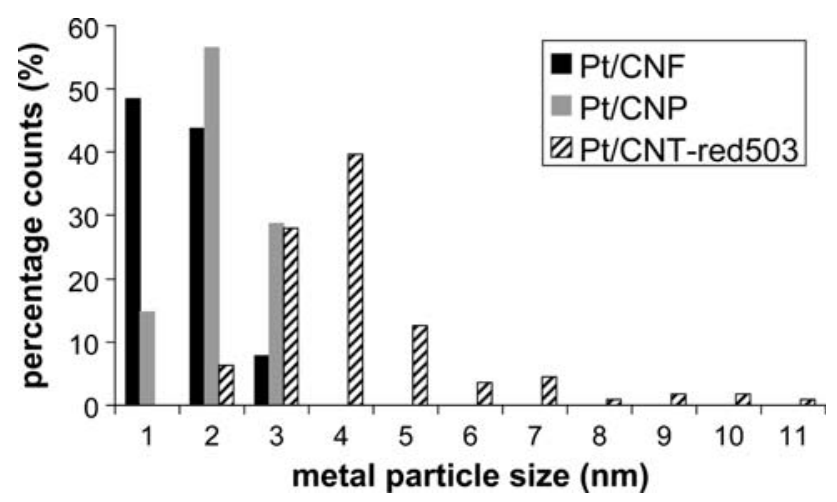

Fig. 5 Histograms of metal particle sizes observed using TEM for $\mathrm{Pt} / \mathrm{CNF}(1-3 \mathrm{~nm}), \mathrm{Pt} / \mathrm{CNP}(1-3 \mathrm{~nm})$ and Pt/CNT-red503 (2-11 nm) sample was indeed larger compared to the one reduced at $473 \mathrm{~K}$, which shows that a higher reduction degree is obtained. Still, the $\mathrm{H} / \mathrm{Pt}$ ratio is lower compared to $\mathrm{Pt} / \mathrm{CNF}$ and $\mathrm{Pt} / \mathrm{CNP}$. TEM analysis of this sample showed relatively large particles, which leads to the conclusion that sintering had occurred. The average particle size for Pt/CNT-red503 determined using TEM $(4.2 \mathrm{~nm})$ and hydrogen chemisorption $(3.2 \mathrm{~nm})$ are relatively close to each other and therefore, it is concluded that reduction at $503 \mathrm{~K}$ resulted in metallic platinum. Thus to summarize, the high amount of acidic oxygen surface groups on CNT results in a high platinum-precursor dispersion. These platinum species are more difficult to reduce and need a higher reduction temperature compared to platinum deposited on CNF and CNP. Once reduced at higher temperature, TEM and hydrogen chemisorption revealed that the platinum particles on CNT were sintered.

The catalysts were tested for the cinnamaldehyde (CALD) hydrogenation (see Fig. 6 for the used abbreviations) and the results are depicted in Fig. 7. Both Pt/CNP and $\mathrm{Pt} / \mathrm{CNF}$ were active $(60 \%$ and $25 \%$ CALD conversion after 300 min respectively), though for the latter catalyst a clear deactivation is observed. For these test reactions by-products (only propylbenzene and $\beta$-methylstyrene) were observed: for $\mathrm{Pt} / \mathrm{CNP}$ this was around $2 \%$ and for $\mathrm{Pt} / \mathrm{CNF}$ this was around $1 \%$. Pt/CNT showed only in the initial state some hydrogenation activity, but deactivated rapidly resulting in no further conversion at all. This also indicates that the standard chosen reduction temperature of $473 \mathrm{~K}$ is not high enough to create an active metal surface. Indeed when the catalyst is reduced at a higher temperature 


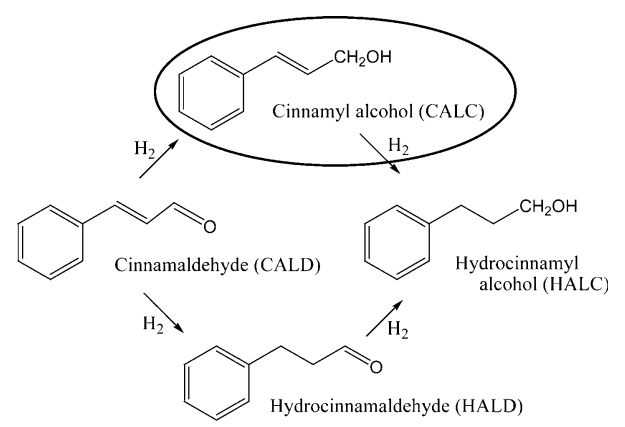

Fig. 6 Hydrogenation pathway of cinnamaldehyde; the desired product is encircled

(i.e. Pt/CNT-red503), hydrogenation activity is observed (Fig. 7) resulting in $13 \%$ conversion after $300 \mathrm{~min}$ of reaction time and about $0.5 \%$ of by-product was observed. This conversion is still substantially lower compared to $\mathrm{Pt} / \mathrm{CNF}$ and $\mathrm{Pt} / \mathrm{CNP}$ (25\% and $60 \%$ respectively).

The initial turn-over frequencies (TOF) are calculated based on $\mathrm{H} / \mathrm{Pt}$ ratios and are summarized in Table 2. The initial TOF is the same for all catalysts, but as mentioned before deactivation quickly starts to affect the catalytic activity for several catalysts. Since the initial TOF is similar for all catalysts, the low weight based catalytic activity of Pt/CNT-red503 must be the result of the lower metal dispersion of that catalyst.

For Pt/CNF, Pt/CNP and Pt/CNT-red503 the conversion of CALD is plotted versus the selectivity to cinnamyl alcohol (CALC) (Fig. 8). The selectivity to CALC for $\mathrm{Pt} / \mathrm{CNP}$ is significantly higher compared to that with $\mathrm{Pt} / \mathrm{CNF}$, while the platinum particle size, amount of oxygen surface groups and TOF is the same for these samples. It is therefore concluded that the selectivity for $\mathrm{Pt} / \mathrm{CNP}$ and $\mathrm{Pt} / \mathrm{CNF}$ changes as a function of the graphene sheet orientation. It is tempting to ascribe this to an electronic effect which has also been used to explain catalytic differences between CNF and CNT materials [5, 24], however that requires more research. For Pt/CNT-red503 the platinum particle sizes, amount of acidic sites as well as the graphene sheet orientation are different compared to $\mathrm{Pt} / \mathrm{CNF}$ and $\mathrm{Pt} / \mathrm{CNP}$. Since it is known that for example variable platinum particle sizes have a significant influence on the catalytic activity [25], it is not possible to establish an intrinsic influence of the CNT graphene sheet orientation with respect to catalytic selectivity.

\section{Conclusions}

Platinum was deposited on nitric acid oxidized CNF, CNT and CNP to investigate the influence of the orientation of the support graphene sheets on the reduction characteristics. The TPR profiles showed that the onset reduction temperature increased from $461 \mathrm{~K}$ for $\mathrm{Pt} / \mathrm{CNF}$ to $466 \mathrm{~K}$ for $\mathrm{Pt} / \mathrm{CNP}$ and $487 \mathrm{~K}$ for Pt/CNT. The reduction temperature for $\mathrm{Pt} / \mathrm{CNT}$ was retarded, which we related to the high amount of acidic oxygen surface groups detected on this support. Therefore, a strong stabilization of the cationic platinum species is observed. Application of the required higher reduction temperature resulted in complete reduction for that sample, however the platinum particle size is then larger $(2-11 \mathrm{~nm})$ compared to that of $\mathrm{Pt} / \mathrm{CNF}$ and $\mathrm{Pt} / \mathrm{CNP}$
Fig. 7 Cinnamaldehyde hydrogenation results of $\mathrm{Pt} / \mathrm{CNP}, \mathrm{Pt} / \mathrm{CNF}, \mathrm{Pt} / \mathrm{CNT}$ and $\mathrm{Pt} / \mathrm{CNT}$-red503. Test reactions were performed at $313 \mathrm{~K}$ under $1,200 \mathrm{mbar}_{2}$ in 2-propanol/ water mixture
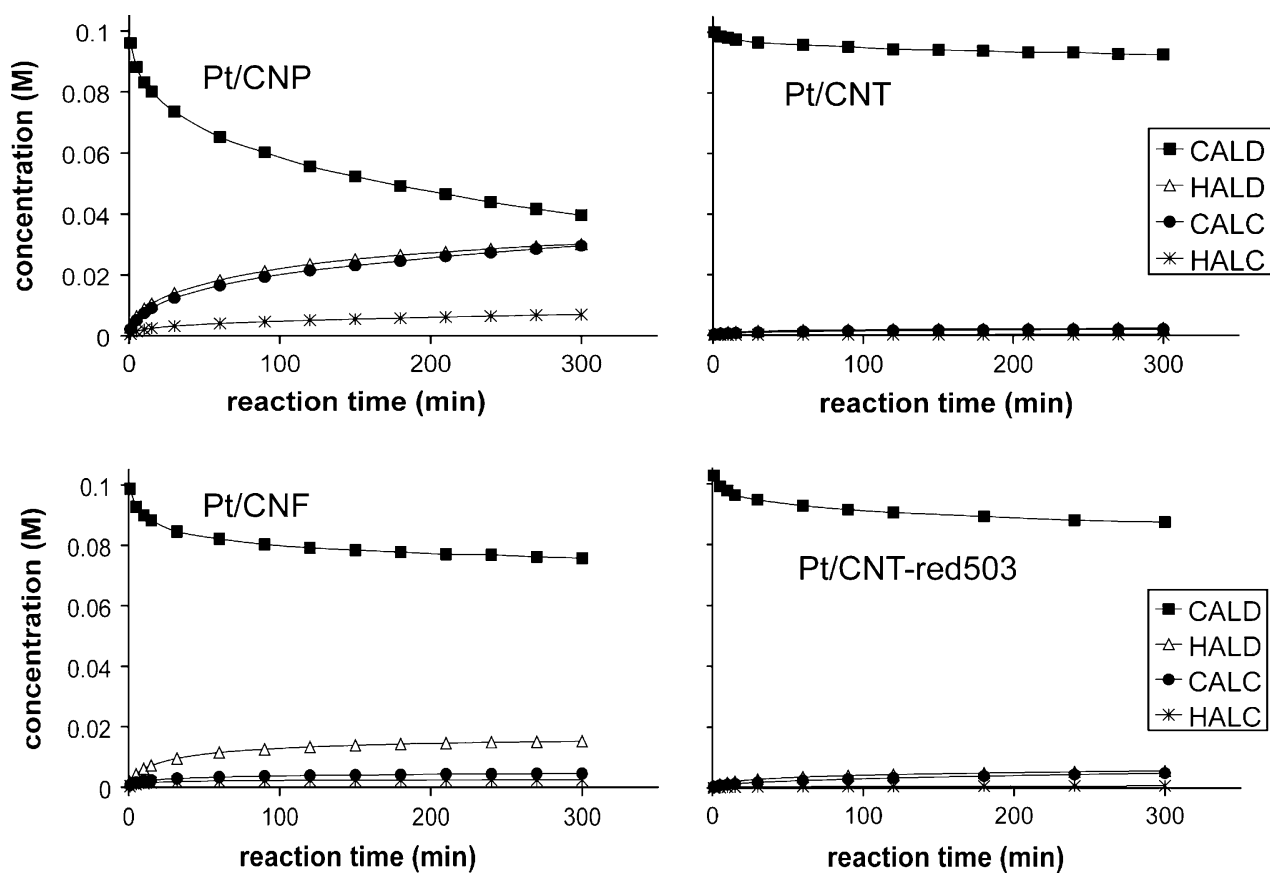


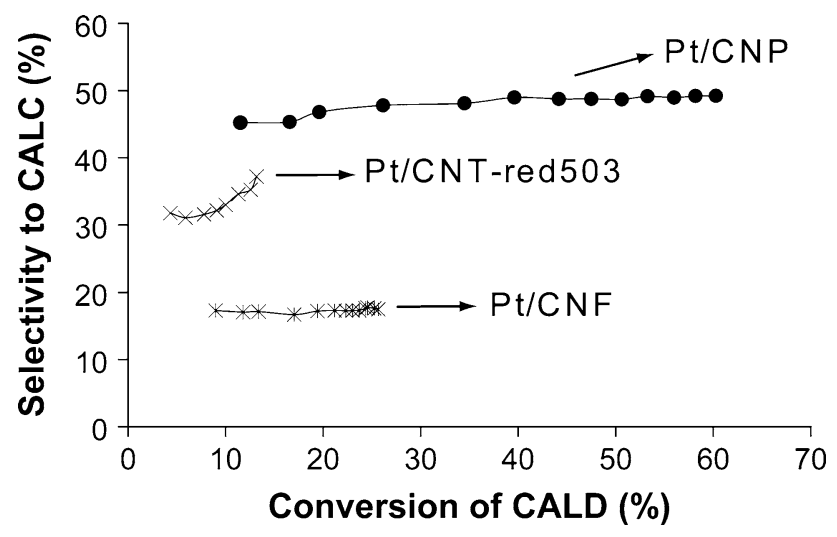

Fig. 8 Conversion vs selectivity for $\mathrm{Pt} / \mathrm{CNF}, \mathrm{Pt} / \mathrm{CNP}$ and $\mathrm{Pt} / \mathrm{CNT}$ red503

(both 1-3 nm). Therefore, the latter two catalysts turned out to be active for the cinnamaldehyde hydrogenation, while reduced platinum on CNT was not very active for this reaction. $\mathrm{Pt} / \mathrm{CNP}$ is more selective towards cinnamyl alcohol in the cinnamaldehyde hydrogenation compared to $\mathrm{Pt} / \mathrm{CNF}$. Since the platinum particle size is the same for both materials, this must be the result of the different orientation of the graphene sheets for the two catalysts.

Acknowledgements The authors wish to acknowledge Ad Mens ( $\mathrm{N}_{2}$-physisorption), prof. ir. John Geus (TEM), Cor van der Spek (TEM) and Helen de Waard (ICP-OES). Financial support was provided by EU Nanocat Project 506621.

Open Access This article is distributed under the terms of the Creative Commons Attribution Noncommercial License which permits any noncommercial use, distribution, and reproduction in any medium, provided the original author(s) and source are credited.

\section{References}

1. Wanke SE, Flynn PC (1975) Cat Rev -Sci Eng 12:93

2. Roman-Martinez MC, Cazorla-Amoros D, Linares-Solano A, Salinas-Martinez de Lecea C (1993) Carbon 31:895
3. Hurst NW, Gentry SJ, Jones A, McNicol BD (1982) Cat Rev -Sci Eng 24:233

4. da Silva AB, Jordao E, Mendes MJ, Fouilloux P (1997) Appl Catal A 148:253

5. Serp P, Corrias M, Kalck P (2003) Appl Catal A 253:337

6. de Jong KP, Geus JW (2000) Cat Rev -Sci Eng 42:481

7. Motoyama Y, Takasaki M, Higashi K, Yoon SH, Mochida I, Nagashima H (2006) Chem Lett 35:876

8. Vu H, Goncalves F, Philippe R, Lamouroux E, Corrias M, Kihn Y, Plee D, Kalck P, Serp P (2006) J Catal 240:18

9. Ma HX, Wang LC, Chen LY, Dong C, Yu WC, Huang T, Qian YT (2007) Catal Commun 8:452

10. Toebes ML, Zhang Y, Hájek J, Nijhuis TA, Bitter JH, van Dillen AJ, Murzin DY, Koningsberger DC, de Jong KP (2004) J Catal 226:215

11. Toebes ML, Nijhuis TA, Hájek J, Bitter JH, van Dillen AJ, Murzin DY, de Jong KP (2005) Chem Eng Sci 60:5682

12. Toebes ML, Bitter JH, van Dillen AJ, de Jong KP (2002) Catal Today $76: 33$

13. Plomp AJ, Vuori H, Krause AOI, de Jong KP, Bitter JH (2008) Appl Catal A 351:9

14. Hao X, Quach L, Korah J, Spieker WA, Regalbuto JR (2004) J Mol Catal A: Chem 219:97

15. van der Lee MK, van Dillen AJ, Bitter JH, de Jong KP (2005) J Am Chem Soc 127:13573

16. Scholten JJF, Pijpers AP, Hustings ML (1985) Cat Rev -Sci Eng 27:151

17. van der Lee MK, van Dillen AJ, Geus JW, de Jong KP, Bitter JH (2006) Carbon 44:629

18. Ros TG, van Dillen AJ, Geus JW, Koningsberger DC (2002) Chem Eur J 8:1151

19. Datsyuk V, Kalyva M, Papagelis K, Parthenios J, Tasis D, Siokou A, Kallitsis I, Galiotis C (2008) Carbon 46:833

20. Toebes ML, van der Lee MK, Tang LM, Huis in 't Veld MH, Bitter JH, van Dillen AJ, de Jong KP (2004) J Phys Chem B 108:11611

21. Zhao TJ, Chen D, Dai YC, Yuan WK, Holmen A (2007) Top Catal 45:87

22. Fraga MA, Jordao E, Mendes MJ, Freitas MMA, Faria JL, Figueiredo JL (2002) J Catal 209:355

23. de Miguel SR, Scelza OA, Roman-Martinez MC, Salinas-Martinez de Lecea C, Cazorla-Amoros D, Linares-Solano A (1998) Appl Catal A 170:93

24. Tessonnier JP, Pesant L, Ehret G, Ledoux MJ, Pham-Huu C (2005) Appl Catal A 288:203

25. Gallezot P, Richard D (1998) Cat Rev -Sci Eng 40:81 